\title{
Women's Perception of Reproductive Illness in Manipur, India
}

\author{
Pebam Krishnakumari, ${ }^{1}$ P. C. Joshi, ${ }^{2}$ M. C. Arun Kumar, ${ }^{1}$ and M. Meghachandra Singh ${ }^{3}$ \\ ${ }^{1}$ Department of Anthropology, Manipur University, Canchipur 795003, India \\ ${ }^{2}$ Department of Anthropology, University of Delhi, Delhi 110007, India \\ ${ }^{3}$ Department of Community Medicine, Maulana Azad Medical College, New Delhi 110001, India
}

Correspondence should be addressed to Pebam Krishnakumari; pebam14@yahoo.co.in

Received 24 October 2013; Revised 15 January 2014; Accepted 29 January 2014; Published 10 March 2014

Academic Editor: Santos Alonso

Copyright (C) 2014 Pebam Krishnakumari et al. This is an open access article distributed under the Creative Commons Attribution License, which permits unrestricted use, distribution, and reproduction in any medium, provided the original work is properly cited.

Perception of reproductive illness by the women themselves is important in understanding the women's reproductive health in a particular society. It also indicates the possibility of taking perception as a tool for measuring reproductive illness. Though women do not have a "germ theory" to explain their reproductive illness they have a sense of illness pathology. Reproductive illness perceived by women is related to physical symptoms and situations in a network of meanings and different meanings are socially generated to articulate their experiences.

\section{Introduction}

Reproductive illness is not only biological but also is embedded in a web of psychological, economic, political, and social factors. Different societies encounter, define, and experience reproductive health problems biologically as well as culturally. Different cultures define reproductive illness in different ways; what is recognised as reproductive illness in one may not be so in others. For this paper, reproductive illness refers to the illness which women perceive as related to their sexual and reproductive organs and function.

As the meaning of health is culturally defined understanding of the women's perception of reproductive health is a sine qua non in order to give a holistic representation of women's health. Here, understanding the conceptual distinction between "disease" and "illness" becomes essential. The concept of disease has historically been the most dominant category; it has a biological interpretation and refers to abnormalities in the structure or function of organ and organ systems, pathological states whether or not they are culturally recognised. Health, as a felt experience of the individual, provides another meaning which is embodied in the term "illness." Thus, illness is the meaning that individual gives to health and refers to a "person" disvalued states including but not limited to disease [1]. Illness is the individual's consciousness that there is something wrong [2]. Thus, disease in the Western medical paradigm is malfunctioning or maladaptation of physiologic processes in the individual. Whereas illness represents personal, interpersonal, and cultural reactions to disease and/or discomfort. Illness is shaped by cultural factors governing perception and labelling explanation and valuation of the discomforting experience and by processes embedded in a complex family, social, and cultural nexus. Because illness experience is an intimate part of social systems of meaning and rules for behaviour, it is strongly influenced by culture: it is, as we shall see, culturally constructed [3].

Perception of reproductive illness by the women themselves is important in understanding the women's reproductive health in a particular society. It also indicates the possibility of taking perception as a tool for measuring reproductive illness. Though women do not have a "germ" theory to explain their illness, they have a sense of illness pathology. Reproductive illness perceived by women is related to physical symptoms and situations in a network of meaning and different meanings are socially generated to articulate their experiences.

Most of the currently known intervention schemes for improving reproductive illness are based on and guided by laboratory test and outsider-based interpretations and 
perspectives of the key factors that affect reproductive health status. Little attempts have been made to investigate how women themselves perceive and understand the aetiology of such illness and how it affects the reproductive health in various societies.

To design a culturally sensitive health programme there is a need to incorporate women's perception of their illness. The meaning of health needs to be recognised for achieving an analytical understanding of the process of production of health as a basis for any realistic and comprehensive effort to improve health condition in the community, as it has a direct bearing on the treatment seeking behaviour. It is high time to look at the "felt needs" of the reproductive health of women. This paper is an endeavour to bring into light how women in Manipur perceive "women's illness" such as vaginal discharge and menstrual problem and their perceptions of the seriousness of different women's illnesses.

\section{Retrospect of Research on Perception of Reproductive Illness}

Medical Anthropology has hitherto been conceived of as a tool for investigating and explicating local perspective on reproductive health. Medical anthropologist has always tended to describe cultural variation in health belief system, emphasizing on people's own description and experience of reproductive health and illnesses within local cultural system.

Way back in the1980s medical anthropologist's ethnographic work primarily focuses on fertility and childbirth. Cormack [4] edited a collection of essays on the cultural construction of fertility and birth in countries like Sri Lanka, New Guinea, Ghana and Britain to demonstrate a wide range of cultural rules and social practices that exist in all societies and influence fertility and childbirth. In India, Jeffery et al. [5] lament out the women's voices reflecting on their experiences of childbearing and provided an accessible and existing reassessment of women's role in an agricultural society traversing a women's life from the time they marry to the moment they enter their husband's household till they give birth. Nichter [6] examined the cultural notion of fertility in Sri Lanka and its impact on family planning practices, as well as the ethnophysiology and food consumption practices during pregnancy in South India. Patel [7] explored how women in Rajasthan have childbirth and postpartum care as their own domain and how their lives showed a mix of subordination and freedom in different spheres of functioning.

In the 1990s health research began to focus on women's perception of reproductive health. Younis et al. [8] assessed the level of reproductive morbidity in Egypt and examined the social context of women's health and attempted to understand women's report of illness in this context. In India, R. Bang and A. T. Bang [9] made an exploration of the perceived causes of white discharge and examined the perceived effect. Evidence suggests that women perceive white discharge to be part of sexual maturation and consider it normal. Studies found that women commonly have multiple terms to refer to different types of vaginal discharge and they linked it to other illnesses, like weakness and backache, and used these terms as euphemisms to report discharge $[10,11]$.

Pachauri and Gittelsohn [12] constructed an ethnomedical model of women's illnesses throwing considerable light on Indian women's perception of their health. Oomman [13] in her study in Rajasthan village emphasised on women's reproductive morbidity within its socio-economic and cultural context and showed how women attributed their illness to their biological susceptibility, which is a result of povertyinduced malnutrition. She also developed an ethnomedical model on the basis of women's perception of severity of "women's illness" which includes discharge (dhola pani), menstrual problem (kapdaro bimari), and prolapse (sharer bahar aaye). In 1999, Patel explored how in practice women manipulate fertility decisions in the light of economic structures on one hand and kinship on the other hand and concluded that fertility behaviour is constituted in dialectical relationship between people and their settings-objective conditions coupled with subjective perspective thereof.

In 2001 Pimpawun Boonmongkon et al. documented from South East Thailand women's experiences of gynaecological complaints linked to the "uterus" (mot luuk) through cultural reasoning. Kaddour et al. [14] elicit the definition of the concept of reproductive health among women in three communities around Beirut, Lebanon. In 2008, Abdul Karim et al. conducted a study to find out community's knowledge and perceived implications of maternal mortality and morbidity in two urban and two rural communities in Borno state, Nigeria. The community members' perception on ways to prevent the scourge was also explored.

Based on a seminal study in a Muslim village in rural Bijnor district (north-western Uttar Pradesh) by P. Jeffery and R. Jeffery [15] argued that government health care provision in rural Uttar Pradesh is embedded in a moral universe characterised by widespread and long-term mistrust of the state services and stressed that encouraging institutional deliveries without addressing the perceptions of potential service users as serious flaw in the approach to reduce maternal mortality. This paper will focus on Andro women's perception on illnesses related to their sexual and reproductive organs and function such as vaginal discharge (phingou chatpa), menstrual-related illness (mangbaga mari leinaba anaba), and prolapse (angangkhao nanthaba). This paper will also emphasize the policy and program including women's perception of reproductive illness.

\section{Methodology}

The information used in this study was gathered during field work conducted between July 2004 and January 2005 updated in 2011. A survey was conducted in September and October, 2004 , to furnish data about the socioeconomic condition of Andro. To get a general perception of women regarding commonly prevalent illnesses among them, free listing technique was used. This method was used to determine the items which make up the domain of "illness which only women get." A master list of women's illness was compiled and used as checked list of illnesses and symptoms. Women 
were chosen randomly from the village for this method. Ten key informant interviews were conducted among old women, traditional healer (maiba), and traditional birth attendant (maibi) of the community to collect information regarding women's illness, causes, childbirth, menstruation, sexual behaviour, food taboo, women's work, and so forth. Women's group like Women's torch bearer (Meira Paibi), Mahila Mandal (name of the women's organisation), traditional birth attendant (maibi), and women of the reproductive age were targeted for the focus group discussions. Three focus group sessions were conducted, each group consisting of 6-8 women. The principal aim during the focus group discussion with women mentioned above was to develop an understanding of women's perception of normal against abnormal vaginal discharge, menstruation, and prolapse and their explanation of the ways in which women acquire, prevent, or deal with such a condition. Special attention was also paid to the association of these perception with a view to obtain a more comprehensive understanding of the causality and sociocultural context in which reproductive illnesses are acquired, the stages, how and why such illnesses occurred, and how they were perceived and managed by the women and their families. Past illness narratives were used on women who have been identified by traditional birth attendant (maibi), traditional healer (maiba), or the women who had particular symptoms like vaginal discharge, menstrual problem, prolapse, and so forth to furnish information regarding illness episode including symptom onset, management, and its perceived consequences on their lives. Seven such narratives were collected for this study.

3.1. Area and People. Andro is a village inhabited by the Lois in Manipur, a state in the north eastern region of India. Etymologically, the word Loi means subdued, dependent, outcaste, and backward. The village is 26 kilometres away from Imphal covering an area of 1211.64 Hectares. The total number of males is 4307 and females is 4437 (Census of India, 2011). There are thirteen localities in Andro.

Agriculture is the mainstay in Andro. It is a family enterprise. However, rice cultivation relies heavily on women's labour. Besides agriculture, brewing liquor, weaving, and potteries are some of the economic pursuit done by women in Andro. Based on the socioeconomic data collected during survey phase in Andro which was conducted in September and October, 2004, 46.9 percent of the females are literate. The mean family income per month in Andro is Rs. 3972.50 (approx. US\$65).

The source of water is one of the indicators of sanitation and hygiene. If there is scarcity of water then women will have to bear the brunt of fetching the water and in maintaining a clean surrounding in their vicinity and in maintaining personal hygiene. In Andro, the main sources of water for cleaning and washing are pond and stream water. However, for drinking and cooking purposes, the main sources of water are spring water, hand pump, and tap water. 25 percent use tap water, 27.5 percent use hand pump, and 49 percent use spring water in Andro as potable water.
The place for throwing waste has an important role to play in adumbrating the sanitation and hygiene of an area. In Andro, there are three ways of throwing the garbage-throw it in the open, throw it in drainage, and dig a pit hole to dump the wastage. A majority (58.5 percent) of the households throw the garbage in the open, 35.5 percent throw in the pit hole, and 6 percent throw the wastage in the drainage.

Having proper toilet facility is essential for healthy existence. In Andro, 0.5 percent do not have toilet facility. 10.5 percent use semipucca, 5.05 percent use pucca, and 81 percent use pit hole, where a hole is dug up and covered on all the four directions with rags.

One of the main factors in health issue is transport and communication. Within Andro people commute in two wheelers like scooter but bicycle is the most common way to glide along. Covering distance by foot is also a common sight in Andro. If one has to go beyond Andro then buses and jeep are the main means of commuting.

In Andro, there is one primary health centre. The main activities carried out in the primary health centre are curative care, tuberculosis detection, maternal, and child health services such as diarrhoea disease control, immunization, and family planning.

3.2. Women's Illness in Andro. Women in Andro perceive illness associated with reproduction as women's illness (nupigi anaba) not as reproductive illness. While conducting interview with the traditional birth attendants (Maibis), local healers (Maiba), and women in the community, certain illnesses were unraveled as experienced only by women. It explicitly shows that there are bouts of illnesses which only women experienced locally termed as women's illnesses (nupigi anaba) in Andro.

During ethnographic study, women spoke about several women's illnesses (nupigi anaba). Checks listing of illnesses was compiled using the findings from free listing method as well as result from key focus group discussion. This list was used to elicit information about each illness on symptom, term descriptions, possible causes, and seriousness of the problem.

Table 1 explicates the main women's illnesses (nupigi anaba) in Andro and was used to elicit information about each illness on symptom, term description, possible causes, and seriousness of the problem.

The free listing method showed that women perceived white discharge (Phingou chatpa) to be the most common problem. Weakness (Sonthaba) and menstrual-related problem (mangbaga mari leinaba anaba) are also frequently mentioned as illnesses indicating that these problems are among the most salient. However, the pile sorting method, focus group session, and in-depth interview with women revealed that uterine prolapse (angangkhao nanthaba), although not reported with high frequency in the free listing results, was a problem which women faced in silence until it disturbs their daily chores.

The local connotation for vaginal discharge is phingou chatpa. In Andro, vagina is used euphemistically as "underneath the cloth." Thus, the word vaginal discharge 
TABLE 1: Women's illnesses.

\begin{tabular}{lll}
\hline Illness term & English translation & Description \\
\hline Phingou Chatpa & White going underneath the cloth & Vaginal discharge \\
\hline Angangkhao nanthaba & Uterus coming out/body falling down & Prolapse \\
\hline $\begin{array}{l}\text { Mangbaga mari leinaba anaba_ee yamna } \\
\text { chatpa, mangba, changnaidaba, puk naba, } \\
\text { ee likna chatpa }\end{array}$ & $\begin{array}{l}\text { Menstrual-related illness-blood going out } \\
\text { profusely, irregular menstruation, stomach } \\
\text { pain, and blood going out scantily }\end{array}$ & $\begin{array}{l}\text { Menstrual problem, heavy period, irregular } \\
\text { period, menstrual cramp, and scanty period }\end{array}$ \\
\hline Khwang naba & Back pain & Pain at the back \\
\hline Chaning naba & Abdominal pain & Pain in the pelvic region \\
\hline Chakmangba/nupamangba & Rice polluted/man polluted & Postpartum illness \\
\hline Puk chakring & Stomach left over & Postdelivery problem \\
\hline Kok ngaoba/Mit tandan paiba & Head spinning/seeing stars & Dizziness \\
\hline Sonthaba & Weakness & Weakness \\
\hline
\end{tabular}

is Phingou chatpa which means discharge coming out of vagina or discharge coming out from "underneath the cloth." Angangkhao nanthaba refers to uterine prolapse which literally means "baby sac slipping out" and Mangbaga mari leinaba anaba refers to problems/illness related to menstruation. The reported menstruation-related illnesses are blood going out profusely (ee yamna chatpa), irregular menstruation (mangba changnaidaba), puk naba (stomach pain), and blood going out scantily (ee likna chatpa). Back pain (Khwang naba) refers to pain at the back along the spinal cord. Most of the women face this problem of back pain several times in their lives.

3.3. Pain in the Lower Abdomen (Chaning Naba). Pain in the lower abdomen (Chaning naba) is one of the problems which women face at different times of their lives. Some women say that they have this pain almost all the time. Some say that this pain is experienced when they work for long in the field or when they lift things which are heavy while others encounter it in their postchildbirth or after sterilization operation stage. Most women say that the pain surfaces up on cloudy days or on rainy days. Relief from this illness is achieved by massaging the abdominal and pelvic area with mustard oil and salt. If the pain persists for long and becomes intolerable then they will call a traditional birth attendant (Maibi)/traditional healer (Maiba) or preferably a traditional birth attendant (Maibi) for massaging the abdomen ( $p u k s u b a$ ). If this does not produce any effect then the woman will see a doctor in the nearest town.

3.4. Pain after Childbirth (Puk Chakring). Pain after childbirth (Puk chakring) is described as the pain which women experience after childbirth. Some of the key informants reported women suffering from severe pain for several days after their last delivery. They were gave different opinion about the perceived cause of such pain. Some said that the pain was basically due to air (nungsit) inside because of the space created in the women's belly after delivery. They believed that pain wanes once the woman starts taking proper food.
Another interpretation is that pain after childbirth (puk chakring) is due to incomplete cleansing of the blood which remains after giving birth to the baby. They believe that if the remnant blood remains inside the body for long then the concerned women will have unbearable pain in the abdomen. So if women have such kind of problem during postpartum period then they seek treatment from the traditional birth attendant (Maibi). The traditional birth attendant (maibi) will massage the abdomen chanting mantras. It is believed that the pain will wane after this enactment.

3.5. Postpartum Illness (Chak Mangba/Nupa Mangba). During postpartum period if proper care is not taken then such illness often happens. Care should be taken properly regarding intake of her food and drinks during this stage and sex should be totally abstained. Rice polluted locally termed as Chak mangba is the condition where the women will lose her tendency to eat. If these conditions prevail then she will puke even at the sight of food. People believe that it will get cured after some months. Care should be taken during postpartum; a woman should drink only boiled water and use warm water. The water which becomes cold after boiling should also not be given because it is believed that this causes diarrhea.

In Andro, a woman is not allowed to have sex after childbirth for three months. If a woman transgresses such restriction then an illness known as "men polluted" locally termed as Nupa mangba occurs to the woman concerned. It is perceived that in the first stage her face will get swollen up, while her hands, feet, and body will shrink. If she does not get any treatment then she will die after some months. People believe that even doctors cannot cure such ailments. It is only the traditional birth attendant (Maiba's)/traditional healer (Maiba) who can cure these types of illnesses.

Weakness (Sonthaba) is an illness as well as the cause of other illnesses like vaginal discharge (Phingou chatpa). Women often reported weakness in association with other illnesses as well as the cause of other illnesses. Women believe that the primary cause for these conditions is work overload and lack of nutritious food. Dizziness (Kok ngaoba) is also another problem reported by women often in association 
with other illnesses. Back pain (Khwang naba) is one major problem in which most of the women are facing. Some have severe back pain in which they have problem in standing up and sitting down. This illness is also associated with other illnesses. Women perceive that back pain (khwang naba) is due to heavy burden of circadian activities.

3.6. Criteria for Selection of Illnesses for Further Investigation. By the term "reproductive illness," we mean indigenously named complaints and conditions that are localized in reproductive organs or are associated with reproductive functions. As this paper aims to look at reproductive health problems, a subset of women's nonpregnancy-related reproductive illnesses was chosen for further investigation based on the following criteria of seriousness and the most common:

(1) most frequently mentioned in the free listing results,

(2) perceived that many women experience the illness,

(3) an illness which women are hesitant to report because of the stigma associated with it and has been unattended to by health providers.

Based on these criteria, vaginal white discharge (Phingou chatpa), menstrual-related illness (mangbaga mari leinaba $a n a b a$ ), and prolapse (angangkhao nanthaba) were looked into for further investigation for symptom, description, etiology, and seriousness of these illnesses as perceived by the women.

3.7. Vaginal Discharge (Phingou Chatpa). In Andro, vagina is used euphemistically as underneath the cloth. Thus, vaginal discharge is Phingou chatpa literally translated as "white going underneath the cloth." Vaginal discharge is categorized into two types - nonbloody and bloody discharge (phingouda ee yaoba). Women in Andro believe that when their body becomes weak they often have discharge. Bloody discharge describes the presence of blood in vaginal discharge. They believe that such a condition is serious and feel the need to attend to it properly.

Women have different perceptions about whom this illness affects and the extent to which Phingou chatpa was prevalent in their village. In one focus group session women unanimously agreed that this illness was prevalent among sexually active women.

Though women reported high prevalence of vaginal discharge (Phingou chatpa) they consider it as normal until and unless it disturbs their circadian activities. Women perceive that everybody has vaginal discharge (Phingou chatpa).

(i) Characteristic of Vaginal Discharge (Phingou Chatpa). Women described vaginal discharge in terms of color, smell, consistency, frequency, and duration. Besides white discharge some women also complained of discharge with blood. They identified it as discharge with banana flower colour (laphutharo machu). Smells are also recognized by women particularly if the discharge is associated with strong and foul smell which made women feel uncomfortable that other people may be able to detect it. Discharge with smell is described by women as foul smell (manam namthiba); women reported the presence of discharge without a smell as odorless (manam namdaba).

Women spoke of having large amount or little discharge and were also able to describe the frequency which they had it every day or sometimes. Women also reported a range of duration for which they experience discharge problem. Some women said they have it before their menstruation for a few days. Illness narratives conducted on women who had reported vaginal discharge (Phingou chatpa) as an illness revealed the typical ways in which it is characterized.

"It is just like having menses. It soiled my wrap around (phanek). I have to wear two wrap around (phanek) at a time" (Mema, 33-year-old woman).

Here, the woman talks about the frequency of vaginal discharge they experience comparing it with the flow of menstruation when the discharge is frequent and quantity is more. In such a situation one had to wear two wraps around (phanek) one on top of the other. The wrap around worn outside conceals the soiled wrap around which is worn inside.

"It is white and has foul smell. It itches a lot too. Whenever I go out I feel so conscious of the smell that I couldn't talk with my friends properly" (Thabalei, 32-year-old woman).

This identifies the women's uncomfortability experienced by the women who had vaginal discharge with foul smell along with itchiness. Thus, women in Andro identified vaginal discharge in terms of color, smell, consistency, frequency, and duration.

(ii) Etiology of Vaginal Discharge (Phingou Chatpa). Women attributed vaginal discharge (Phingou chatpa) to several different causes. Causes listed in Table 1 were most frequently mentioned by women in depth interview and in pile sorting of illnesses. Weakness (sonthaba), worry (wakhal waba), anger (asaoba), overload of work (thabak henba), conditions produced by economic hardship were felt to cause vaginal discharge (Phingou chatpa). Women also perceived that eating fruits and avoidable food during menstruation and post-artum period transforms blood to water leading to vaginal discharge (Phingou chatpa). Other factors believed to cause vaginal discharge (Phingou chatpa) were related to events like sterilization operation, wearing an intrauterine device, abortion, and childbirth.

During illness narrative interviews, women reported that the onset of vaginal discharge (phingou chapta) occurred often because of one or more of these events. Some women who had vaginal discharge (phingou chapta) at the time of interviewing said that they have no idea why they had this illness. Interview conducted with woman provides examples of woman's perception regarding the causes of such illness.

Chingabham Tombinou, traditional birth attendant (Mai$b i)$, retorts "Young women start wearing inners (Panties) which obstruct the circulation of the blood and causes many illness like vaginal discharge which is actually blood turned to water. Moreover, they do not restrict on tabooed foods which are supposed to be kept at bay during menses and postpartum period." 
Women perceived that wearing panties obstructs the flow of menstrual blood turning blood into water thereby causing vaginal discharge. In Andro, there are certain food items which are restricted to be taken during menstruation and postpartum period. The verbose of the traditional birth attendant implies that women have vaginal discharge as they did not put any restriction on eating the tabooed food during menstruation and postpartum period.

However, women in Andro unanimously agreed that daily hard toil to make both ends meet is the root cause of discharge. There is a saying in Andro "If you don't work then you starve." Economic crunch in a household affects women. Engaged in a daily struggle to meet the basic needs, they cannot spare time to improve and safeguard their own health. Economic hardship compels women to work hard to make both ends meet. This leads to physiological weakness, which in turn deteriorates the health condition and causes all illnesses. The price of poverty has to be paid by women as poverty makes them compromise on their health.

"When a woman is pregnant or during postpartum period a woman is supposed to be fed with nutritious and strengthening food but when you don't have the money to buy then you have to survive on whatever is available. This deteriorates the health condition of woman and invites all ailments including vaginal discharge (Phingou chatpa)". (Daya, 34-year-old woman from Andro)

"Woman eats whatever is growing in their kitchen
garden. They cannot afford to have nutritious food
like milk, nuts, meat, and so forth, to supplement
their diet. Rice and curry are their staple food.
This weakens a woman's body moreover, a child
bearing mother. Thus most women in Andro suffer
from vaginal discharge." (Memcha, 37-year-old
woman from Andro)

The above verbose explicates the brunt women have to bear due to their impoverished condition. It reveals the inability of women in Andro to have the luxury of having nutritious food when it is considered to be a requirement during pregnancy and postpartum period due to economic crunch and how it became the root cause of vaginal discharge.

Women also relate their symptoms to different procedures or conditions that they had undergone. Some blamed it on abortion, insertion of IUD, and unhygienic way of living as a probable cause of vaginal discharge. Women in Andro associate vaginal discharge (Phingou chatpa) with poor perineal hygiene and by working in dirty water in the rice field. Some of the women perceive that vaginal discharge (Phingou chatpa) can be transmitted from husband and can happen due to lack of nutritious food. Thus, women have diversified opinion regarding the etiology of vaginal discharge but they unanimously agreed that their impoverished condition is the root cause of vaginal discharge.
Economic burden of a family is borne by the women and it is women who suffer.

(iii) Seriousness of Vaginal Discharge (Phingou Chatpa). Women believe that an illness is serious for particular reasons. Vaginal discharge (Phingou chatpa) is perceived as a problem when the discharge is an excess. In an in-depth interview

Thaba (a woman from Andro) said "If the discharge wets the wrap around (phanek) then the condition is serious."

"When the discharge is like the menstrual flow then it is a serious case".(Tampha, 34-year-old woman).

In Andro women wear wrap around known as phanek. If the discharge is heavy like the menstrual flow, and when it soils the wrap around then, such a condition is considered to be a serious case of discharge. Women use onomatopoeic terms like o-ro-rochatpa (going) and jo-ro-rochatpa (going) to explain the severity of vaginal discharge. Women compare the severity of vaginal discharge allegorically with the menstrual blood flow.

Women in Andro also perceive discharge to be serious when there is blood in it. Driving home this point is Moyonsakhi's assertion that "If there is blood in discharge then it is a problem that needs to be looked into."

The above finding explicates that women perceive vaginal discharge (Phingou chatpa) as serious when the discharge is in excess which they describe in onomatopoeic terms like oo-ro-rochatpa (going) or jo-ro-rochatpa (going). The seriousness of vaginal discharge (Phingou chatpa) was also described allegorically with the menstrual blood flow. They also perceived that vaginal discharge (Phingou chatpa) is serious when there is blood in discharge.

3.8. Menstrual-Related Illness (Mangbaga Mari Leinaba Anaba). Menstrual-related illness (Mangbaga mari leinaba anaba), a common complaint among women, is a collective term for different illnesses/problems associated with menstruation. Women describe heavy menstruation as a debilitating illness which sucks out all their strength. Menstrual cramp was not considered as a serious illness. Women generally endure or bear the pain by lying down or using hot water bottle/water bag. Other menstrual problems like irregular menstruation and scanty period were also reported.

(i) Causes of Menstrual-Related Illness (Mangbaga Mari Leinaba Anaba). The causes of menstrual problem which women perceive include wearing panties, using pads, eating avoidable food during menstruation, abortion, insertion of IUD, sterilization operation, pregnancy, delivery problems, and improper cleaning during childbirth. Interviews with women provide examples of women's beliefs about the causes of menstrual problem.

Hemsori, a 50-year-old traditional birth attendant (maibi) from Andro, Cites the reasons for menstrual problem: "If 
the remnant blood after delivering the baby is not cleaned properly then it happens."

As cited by the traditional birth attendant one of the perceived cause of menstrual problem is improper cleaning of blood after childbirth. Others reason out on utilization of contraceptive device like $\mathrm{Cu}-\mathrm{T}$ and sterilization operation as the root cause of menstrual problem. This is supported by the following citation.

Another 45-year-old woman from Andro describes the reasons for menstrual problem: "Women started putting foreign particle inside their body (copper-T) and had operation. All these block their tubes which lead to menstrual problem."

Thus, women in Andro perceived that the causes of menstrual problem are improper cleansing of blood after delivery, insertion of IUD, and sterilization. However, these are the proximate factors responsible for menstrual-related illness.

(ii) Seriousness of Menstrual-Related Illness (Mangbaga Mari Leinaba Anaba). Menstrual disorders are perceived as a problem with which woman have to live and suffer. One of the menstrual problems which is perceived to be the most serious is heavy menstruation. They believe that heavy menstruation drains away all the strength and is considered to be weakening and cause dizziness and exhaustion.

Though heavy period is considered a serious case, women do not seek any treatment. Menstrual disorders are perceived to be a problem which women have to suffer in silence. Engaged in their daily struggle to meet the basic needs, they cannot spare time to improve and safeguard their own health. Above all they cannot afford to spend money on illness which did not disturb their daily activities. Thus, the price of poverty has to be paid by women by compromising on their health.

3.9. Prolapse (Angangkhao Nanthaba). Prolapse (Angangkhao nanthaba nanthaba) is literally translated as baby sac slipping out. Women do not make any distinction between vaginal and uterine prolapse. They simply refer to a feeling of heaviness "down below" or that "something coming out" of vagina. Women believe that prolapse is an illness which needs attention from allopathic health care provider because there is no local treatment for it.

(i) Characteristics of Prolapse (Angangkhao Nanthaba). Different types of prolapse that women experience are described. They have constant feeling of heaviness below or as if something is falling out from below making them difficult to sit, stand, or walk. This makes them so inconvenient and disturbs their daily activities. This is associated with severe back pain. They cannot stand up abruptly after sitting also. Prolapse interferes with women's work activities and with their lives. The degree to which they feel inconvenient by a prolapse depends on "how much the body is coming out." Women say that they have difficulty lifting weight and difficulty in urinating when they have prolapse.

(ii) Causes of Prolapse (Angangkhao Nanthaba). Women in Andro gave different version for causes of prolapse (Angangkhao nanthaba). Women believe that prolapse occurs due to long and difficult labour problem, carrying heavy items during postpartum period, sterilization, frequent abortion, and frequent childbirth. Interviews with women provide example of beliefs about causes of prolapse.

"Frequent childbirth and abortion spoils the body. Playing with your body is not good. The pulling and pushing, inserting instruments and hand inside the delicate women's body will destroy everything" (Monsori, 43-year-old woman from Andro).

During childbirth, if the fetus did not come out as soon as the amniotic sac bursts then the traditional birth attendant (maibi) has to pummel the stomach and insert the finger inside the vagina to pull the fetus out. Simultaneously, the woman in labour was encouraged to push harder to accelerate the birth of the child. Some women remarked how this kind of pulling and pushing leads to prolapse.

Women also believe that lifting heavy weights also causes prolapse. In their day-to-day activities, a woman routinely lifts heavy weights. This includes lifting and carrying heavy pots of water from the ponds, hand pumps, and tap to the house. Lifting heavy weight especially just after childbirth is considered to be dangerous because woman's body during this stage is still tender and lifting heavy weight could push the body out.

It is believed that performing heavy activities can lead to prolapse (Angangkhao nanthaba) as a woman relates: "If you lift heavy things during the post delivery period when the body is tender after giving birth then you will have prolapse (Angangkhao nanthaba). It is like the womb collapses and comes out. It is not painful but it is very uncomfortable."

Women also perceived that sterilization operation and inserting Copper-T (IUD) cause this problem because it weakens the body and makes it easier for the body to come out. Thus, women believe that problem during childbirth, lifting heavy weight, or undergoing a sterilization operation are susceptible to prolapse (Angangkhao nanthaba).

(iii) Seriousness of Prolapse (Angangkhao Nanthaba). Prolapses (Angangkhao nanthaba) were unanimously perceived by the people and traditional birth attendant (Maibi) which needs to be addressed by a doctor. Women consider prolapse (angangkhao nanthaba) a serious illness which needs medication from allopathic provider. They consider prolapse (angangkhao nanthaba) serious when they see/feel the body parts coming out.

The traditional birth attendant (maibi) also puts their hands up in such case. Monsori, a maibi in Andro commented:

"This is a serious problem because there is no treatment for this illness. One has to operate to lift up the Angangkhao (baby sac) at a big hospital which most of the women cannot afford. So, until and unless it disturbs the daily domestic chores one will not get treatment."

Women in Andro believe that many women suffer from prolapse (angangkhao nanthaba) but they suffer in silence 
as financial problem refrains woman from seeking timely care. Thus, it is a setback that women in Andro have to suffer because of their reproductive caliber due to financial constraint.

\section{Discussion and Conclusion}

Women in Andro refer to health problem relating to reproductive organ and function not as "reproductive illness" but as women's illness (nupigi anaba). Though women do not have a "germ theory" of illness, they have a sense of illness pathology. Women attributed their illnesses to several different causes such as heavy workload, sterilization, after insertion of IUD, wearing panty, eating avoidable food, and improper cleansing after childbirth. However, women in Andro unanimously perceived that poverty is the root cause of women's illness. Economic crunch in a household affects women. Engaged in a daily struggle to meet basic needs, they cannot spare time to improve and safeguard their own health. Economic hardship compels a woman to work hard to make both ends meet. This leads to physiological weakness, which in turn deteriorates the health condition and causes all the illness. The price of poverty has to be paid by women as poverty makes them compromise on their health. Conditions directly resulting from poverty include anger, worry, lack of nutritious food, and hard toil. These conditions will produce physiological weakness (sonthaba). This physiological weakness is brought about by economic hardship. They fundamentally believed that the treatment of such illness is possible only when their lives are economically improved. Women believe that when they are physically weak they are susceptible to other factors causing vaginal discharge (Phingou chatpa), menstruation-related illnesses (mangbaga mari leinaba anaba), and prolapse (angangkhao nanthaba). These factors are referred to as "susceptibility" factors [16]. The proximate factors may be categorized in the following manner: problem after sterilization operation or after insertion of Copper-T, problem after a spontaneous or induced abortion, childbirth and delivery problem, lack of nutritious and strength giving food, problem of violation of food taboo during menstruation and postpartum period, problem with transmission of illness through sexual intercourse from man to women, and problem of lifting heavy weights.

The finding explicates that women's perception of reproductive illness succinctly differs from the biomedical definition of reproductive disease. Meanings are embodied in the term "women's illness" and symptoms are filtered through the world view of the people. Reproduction is perceived to be the sole responsibility of women; thereby the term women's illness (nupigianaba) for illness associated with reproductive organ. The aetiology, progression, and seriousness of illness are also filtered through the world view of the women and this will have a direct bearing on treatment.

Illness described by the term Phingou chatpa is related to physical symptoms and situation in a network of meanings and different meanings are socially generated by individual to articulate their experiences. The findings show that vaginal discharge (Phingou chatpa) is used with other physical symptoms such as weakness. Additionally, the finding explicates that women describe the feeling of impoverishment in connection with vaginal discharge (Phingou chatpa). In other words, women can report vaginal discharge (Phingou chatpa) if she is impoverished and feels weak although she might not have physical symptom of vaginal discharge or if she has normal physiological discharge. Thus, an illness is the meaning that women give to health and refers to a person's perception and experiences of certain socially disvalued status. The meaning of health needs to be recognized for achieving an analytical understanding of the process of production of health as a basis for any realistic and comprehensive effort to improve health condition in a community, as it has a direct bearing on the treatment-seeking behavior.

We would like to highlight the need to incorporate women's perception of reproductive illness while designing reproductive health programs which are culturally sensitive to bridge the gap between what is considered as the need and the actual need at the grassroots level. Reproductive health programs should include men and women and be introduced within a larger development project that addresses poverty and livelihood issues. The project can focus on developing human capacity to generate income for households and thereby addressing the primary needs of the local community. In the process of addressing the "root cause" (poverty) of women's illnesses an approach towards women's reproductive health can also be considered simultaneously. If women feel that they have time and money to attend to their own health they will be more willing to participate in a reproductive health program. If poverty alleviation program can be developed then local men will be more willing to understand the reproductive health needs of their wives and encourage them to participate in the program.

Innovative health program which will provide women (including men) with the knowledge to understand the "pathology" of disease within the context of their lives can be created. Gradually, as biomedical model of disease interacts with the women's perception of illness, they may begin to distinguish physical symptom of sickness from other "meanings" of sickness and report these as symptom to a health provider. On the other hand, health provider should understand the complexity of the reported symptom and not assume that a reported symptom correlates with disease. Thus, reproductive health program can be more innovative and touch the life of the women concerned thereby approaching towards the "felt needs."

\section{Conflict of Interests}

The authors declare that there is no conflict of interests regarding the publication of this paper.

\section{References}

[1] A. Young, "The anthropologies of illness and sickness," Annual Review of Anthropology, vol. 11, pp. 257-285, 1982.

[2] R. Frakenberg, "Medical anthropology and development: a theoretical perspective," Social Science and Medicine, vol. 14, pp. 197-207, 1980. 
[3] A. Kleinman, L. Eisenberg, and B. Good, "Culture, illness, and care. Clinical lessons from anthropologic and cross-cultural research," Annals of Internal Medicine, vol. 88, no. 2, pp. 251258, 1978.

[4] M. C. P. Cormack, Ed., Ethnography of Fertility and Birth, Academic Press, London, UK, 1982.

[5] P. Jeffery, R. Jeffery, and A. Lyon, Labour Pains and Labour Power: Women and Childbearing in India, Zed Publishers, London, UK, 1989.

[6] M. Nichter, "Idioms of distress: alternatives in the expression of psychosocial distress: a case study from South India," Culture, Medicine and Psychiatry, vol. 5, no. 4, pp. 379-408, 1981.

[7] T. Patel, "Women's work and their status: dialectics of subordination and assertion," Social Action, vol. 37, no. 2, pp. 126-149, 1987.

[8] N. Younis, H. Khattab, H. Zurayk, M. El-Mouelhy, M. F. Amin, and A. M. Farag, "A community study of gynecological and related morbidities in rural Egypt," Studies in Family Planning, vol. 24, no. 3, pp. 175-186, 1993.

[9] R. Bang and A. T. Bang, "Women's perceptions of white vaginal discharge: ethnographic data from rural maharashtra," in Listening To Women Talk About Their Health: Issues and Evidence From India, J. Gittelsohn and M. E. Bentley, Eds., Ford Foundation, Har-Anand Publications, New Delhi, India, 1994.

[10] S. Kanani, K. Latha, and M. Shah, "Application of qualitaive methodologies to investigate perceptions of women and health practitioners regarding women's health disorders in baroda slums," in Listening To Women Talk About Their Health: Issues and Evidence From India, Ford Foundation, J. Gittelsohn and M. E. Bentley, Eds., Har-Anand Publications, New Delhi, India, 1994.

[11] T. Patel, Fertility BehAviour: PopulAtion And Society in A RAjAsthAn VillAge, Oxford University Press, New Delhi, India, 1994.

[12] S. Pachauri and J. Gittelsohn, "Summary of research studies and implications for health policy and programmes," in Listening To Women Talk About Their Health: Issues and Evidence From India, J. Gittelsohn and M. E. Bentley, Eds., Har-Anand Publications, New Delhi, India, 1994.

[13] N. M. Oomman, Poverty and Pathology: Comparing Rural Rajasthani Women's Ethno-medical Models with Biomedical Model of Reproductive Behaviour [Ph.D. thesis], John Hopkins University, Baltimore, Md, USA, 1996.

[14] A. Kaddour, R. Hafez, and H. Zurayk, "Women's perceptions of reproductive health in three communities around Beirut, Lebanon," Reproductive Health Matters, vol. 13, no. 25, pp. 3442, 2005.

[15] P. Jeffery and R. Jeffery, "Only when the boat has started sinking: a maternal death in rural north India," Social Science and Medicine, vol. 71, no. 10, pp. 1711-1718, 2010.

[16] H. Zurayak, H. Khattab, N. Younis, and M. El-Mouelhy, "Concepts and measures of reproductive morbidities in rural Egypt," Studies in Family Planning, vol. 3, no. 1, pp. 17-40, 1993. 

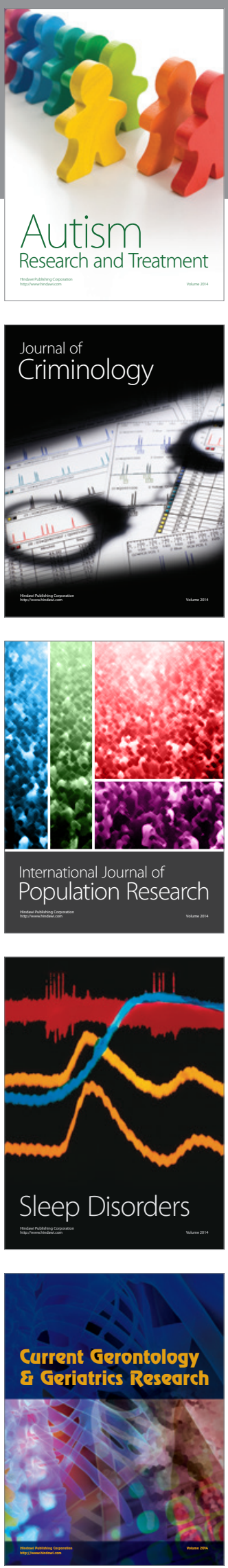
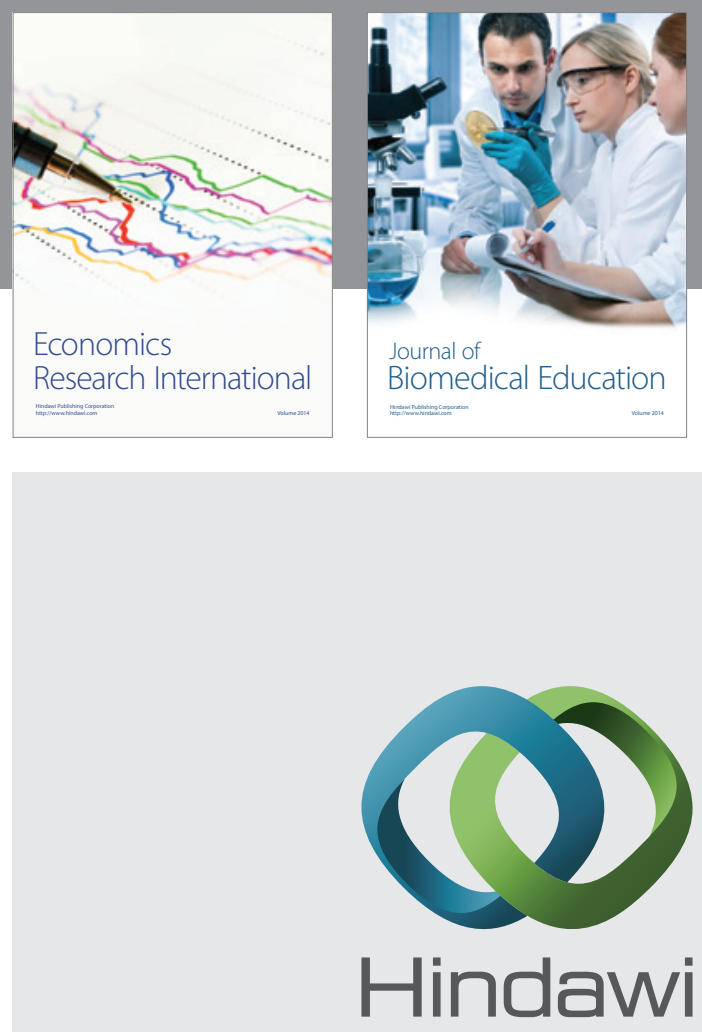

Submit your manuscripts at

http://www.hindawi.com
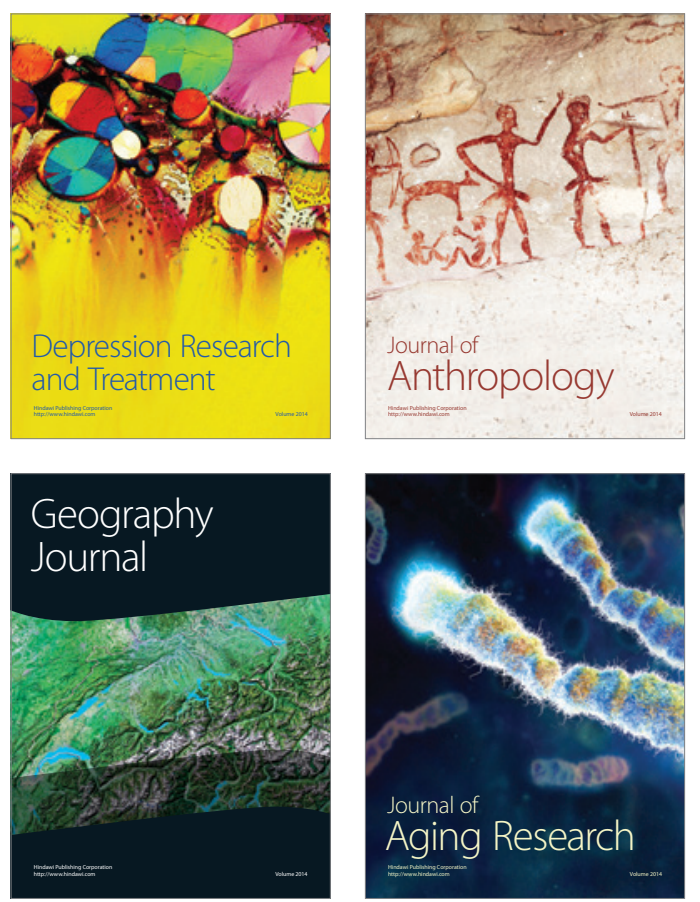
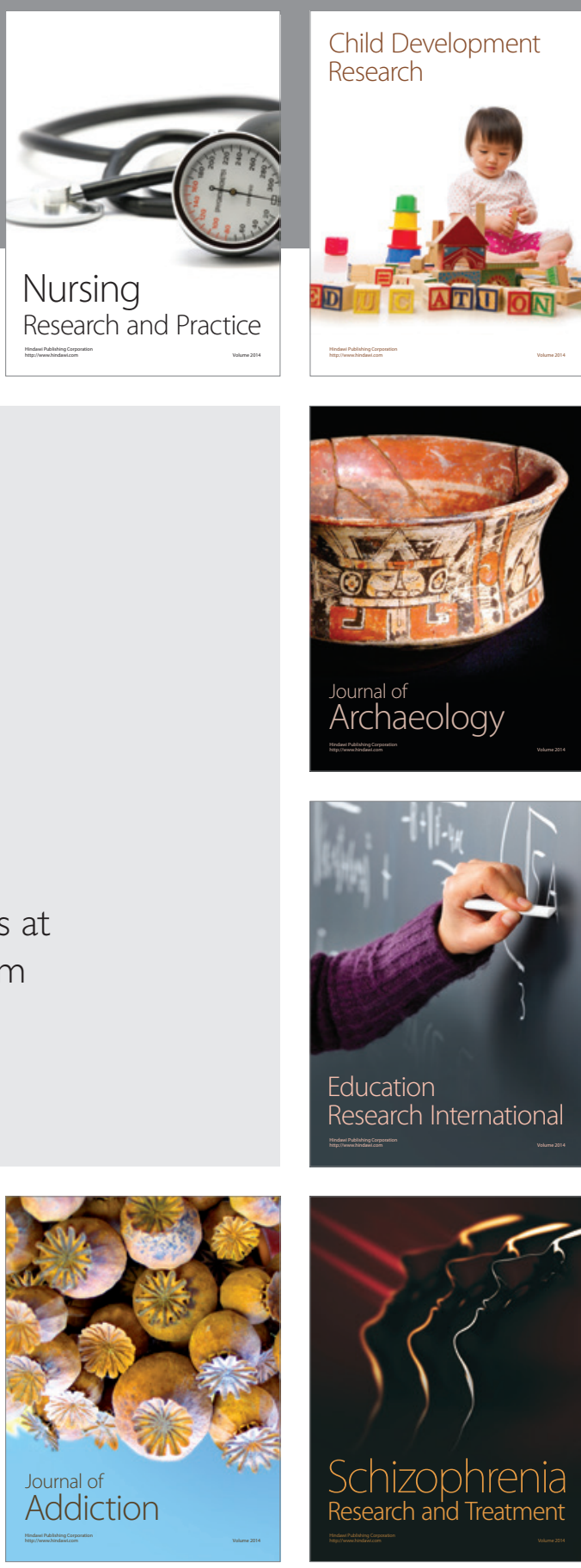

(D)
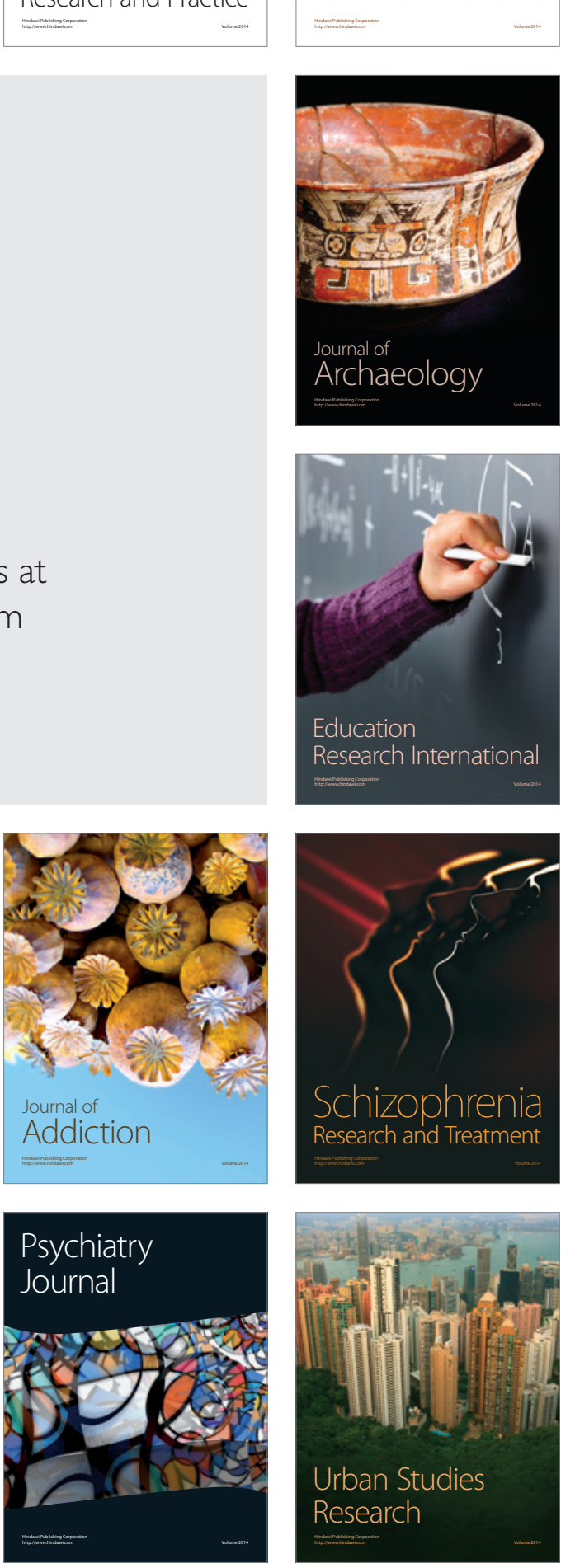